\title{
Investigate and analysis the efficiency of photovoltaic system with active cooling based on numerical method
}

\author{
Nabeel Mohamed akram Samad ${ }^{1}$, Khaleel Ali Khudhur ${ }^{2}$, Ghanim Thiab Hasan ${ }^{3}$ \\ ${ }^{1,2}$ Northern Technical University, Kirkuk Technical College, Kirkuk, Iraq \\ ${ }^{3}$ Sharqat Engineering college, Tikrit University, Tikrit, Iraq
}

\section{Article Info \\ Article history: \\ Received Dec 12, 2020 \\ Revised Oct 15, 2021 \\ Accepted Oct 25, 2021}

\section{Keywords:}

Active cooling

CFD simulator

Flow optimization

Photovoltaic-thermal system

\begin{abstract}
The aim of this research is to establish a simulation model to examine the performance and working efficiency of a solar cell system by using computational fluid dynamics (CFD). The proposed model consists of a water feed tube and an absorber plate, as well as a convection heat transfer system, the ansys fluent system simulation program was used. The electrical output of the panel and its efficiency have been investigated and the effect of changes in the intensity of solar radiation on the temperature of the liquid and the absorption plate on the performance of the system have been studied. A dynamic analysis of the thermal hybrid system was performed with a circulation pump. Calculations were performed using a detailed mathematical model. The analysis was performed in three cases, the first case when the system has no cooling, in the second case with constant flow, and in the third case when the pump was optimized. Finally, numerical results were compared with the practical reference results. Both results are in good agreement. The results obtained showed that the system with optimization case give a good improvement in efficiency with low reduction of the thermal efficiency compared to a constant flow.
\end{abstract}

This is an open access article under the CC BY-SA license.

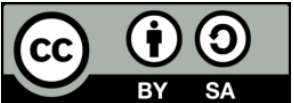

\section{Corresponding Author:}

Ghanim Thiab Hasan

Department of Electrical Engineering

Tikrit University, Sharqat Engineering College, Tikrit, Iraq

Email: ganimdiab@yahoo.com

\section{INTRODUCTION}

Because conventional energy sources such as coal, oil and gas are limited and exhausted, and due to the energy is considered to be the main cause of environmental pollution, energy must be produced from renewable energy sources. Since the solar energy is considered as inexhaustible source and an environmental friend [1], when the light falls on the surface of the solar cell, the photovoltaic cells will operate and produce electrical power in its output connected to the supply of the consumed electric power lines, so, it is considered as another source of electricity [2]. In this process, only a small part of the solar radiation energy is converted into electrical energy, while another energy part of the incident solar radiation falls on the panel surface is converted into heat, which leads to an increase in the temperature of the cell which leading to a decrease in the panels efficiency for about $0.5 \% /$ Kelvin [3]. Some recent studies carried out in this field have demonstrated that when sufficient mass current is provided at the low input temperature, an acceptable improvement in electrical efficiency can be achieved [4]. The excess thermal energy resulting from cooling the cell can be used to prepare hot water in homes or as hot water in baths designated for swimming, the overall efficiency of the system can be increased by increasing the amount or level of coolant flow and this requires additional electrical energy for the pumps, and this leads to a reduction in the electrical efficiency resulting from this system [5]. 
This work describes the method to control the pumping power (liquid flow) in order to increase the output of solar panel. The economic inefficiency of non-conventional against conventional electrical energy sources is a main subject. It is precisely for this reason that this document reports on the dynamic analysis of increasing of the output of the system. We can now see how the energy of the hybrid photovoltaic (PV) system improves the whole system efficiency due to the thermal energy generated, which can be used in a home environment, but because of the electrical pump's energy requirements, electrical efficiency falls at a constantly high rate of flow. It is therefore necessary to optimizing this system with the adjustable size in the mass flow system, monitoring the dosing variation for the panel and the panel temperature in order to get optimum output power from the grid, the photovoltaic thermal panels and the optimization of the system. Some researchers investigated and studied the efficiency of photovoltaic system with active cooling such as:

- Selmi et al. [6] who modelled the mechanisms of solar radiation, convection and heat transfer by using the computational fluid dynamics (CFD) method. He was concluded that in case of using the forcing tap the fluid will has a much lower temperature in comparison with the non-flowing water. A related test project was improved in order to study the simulation model. The simulation and measurement results are approximately identical.

- Cunha and Eames [7] have developed a numerical simulation model for comparing a hybrid photovoltaic thermal (PV/T) system with the photovoltaic module. Thermal and electrical sections were mixed in a metaphysical' modelling. The effects of some parameters such as radiation, temperature, inlet temperature and inlet speed have also been studied. The conclusion was that hybrid (PV/T) system is useful to be used in regions where solar radiation and room temperature are high.

- A dynamical simulation module was performed by Bhattarai et al. [8] who compared the effectiveness of the hybrid PV/T and metal pipe systems with a collector. They developed uni-dimensional solution by resolving energy conserving solutions for several portions of a given system at the same time. Numerical results were matched to the measurements of the underlying data in the present experiment. It was found that the daily heat efficiency of solar collectors is about $19 \%$ greater than that of the solar system $(\mathrm{PV} / \mathrm{T})$. Whereas the primary power consumption of the systems (PV/T) conserved more than the photovoltaic collectors [9].

- A hybrid PV/T system experimental prototype was established by Haurant et al. [10], [11] during eighteen months. They supplied a simulation model for (PV/T) system as given in TRNSYS. The simulation software. The results of the simulation are compared with the actual data observed. A high level of consensus has been found between the results of the simulation and the experiment results.

\section{PROPOSED PHOTOVOLTAIC-THERMAL SYSTEM}

The PV system includes a solar panel with a total surface area of $23.80 \mathrm{~m}^{2}$. The module converts the sun's energy into electrical power. The heating part of the system is made up of the absorbing plate that must transfer the heating energy of the panel surface to the circulating water. The heating exchange takes place in the water reservoir, in which the warm water is led to the upper part of the reservoir, whereas cold water will be in the container base. The cold water is directed to the bottom of the solar panel by the circulating pump with the mass flow present.

The photovoltaic system is designed so that the simple photovoltaic panels are positioned on top of the collector. The system comprises a glass covering plate that absorbs light into the absorber, photovoltaic that convert the sun's energy into instant power, and an absorbing plate that transfer the thermal energy to the flowing water. A schematic diagram of the proposed photovoltaic thermal system is illustrated in Figure 1.

The pump is a component of a solar thermal system whose task is to keep the desired current across the bottom of the panel. In this way, the thermal energy produced by the panel and cooling it is realised. In order to maintain the required flow, the pump's necessary electrical power is determined by using (1) [12],

$$
\mathrm{Pp}=\frac{\mathrm{K} \cdot \mathrm{m}^{3}}{2 \mathrm{~A}_{\mathrm{C}}^{2} \cdot \varphi^{2} \cdot \eta}
$$

where:

$\mathrm{K}$ : Represent the overall loss coefficient, $\mathrm{m}$ : but the flow, $\rho$ liquid density, Ac: cross section area of the pipe and $\eta$ : pump efficiency.

From (1), we can see that only variable parameter is the mass of the fluid, while others are almost constant. Other parameters are depending on the fluid physical characteristics. Electrical energy needed for the operating of the pump is an exceeding non-linear function. This required energy is cubic increases in relation with the increasing of the flow mass. 


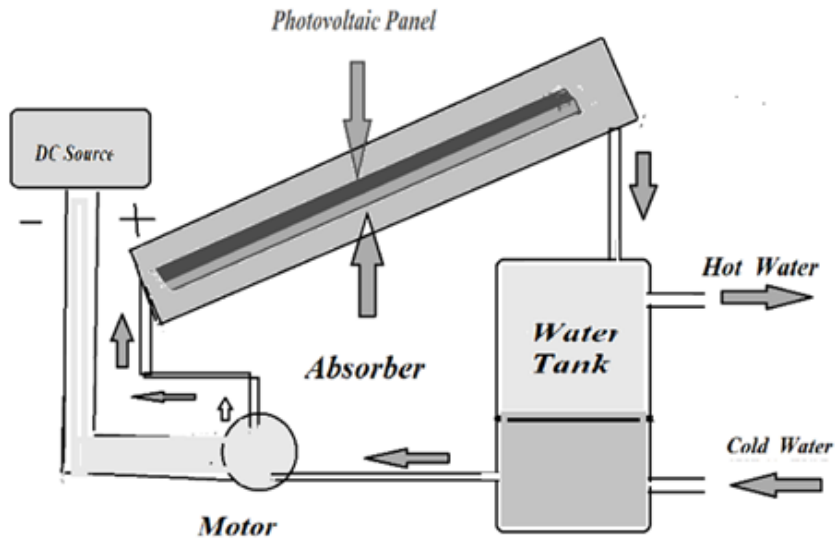

Figure 1. System block diagram

\subsection{Effect of temperature on the characteristics of the photovoltaic panel}

Any change in the panel surface temperature will led to several changes in the characteristics of the photovoltaics. To examine the properties of the panels, it is necessary to determine the way in which temperature influences the panel parameters: short circuit currents Iks, open circuit voltage $U o k$, maximum power $P m$ and panel efficiency $\eta$. It is common for the efficiency to decrease by about $0.5 \%$ with an increase in panel temperature of $1^{\circ} \mathrm{C}$. The reason for this is that any increase in temperature will results in reduction in the width of the banned belt, causing a slight increase in saturation current, but the increase in temperature increases the kinetic energy of the molecules, resulting in a decrease in the P-N junction electrical field. The reduction of the electric field causes the electrons and the cavities to recombine more rapidly, which ultimately results in a reduction of the open-circuit voltage. Temperature change affects the open-circuit voltage. The current of the Iks circuit can be obtained by the following [13],

$$
I_{K s}=N L^{3} \exp \exp \left(-\frac{q U_{O k}-E_{g}}{K T} \pi r^{2}\right.
$$

where: A represent the collector area, T represent the collector temperature, q-surcharge (1.602*10-19 C), open circuit voltage Uok, forbidden egg transport width $(\mathrm{eV})$, K-Boltzmann constant.

\section{MATHEMATICAL CALCULATIONS}

\subsection{Calculation of the total panel irradiance}

The electrical energy of the photovoltaic panel is often determined by a high dose of sun energy.

The sun's dose on the sloping surface Itt can be calculated with the next [14],

$$
I_{t t}=I_{b, t}+I_{r, T}+I_{d, T}
$$

where: $I_{b, t}$ is the direct sunlight strike the sloping surface, $I_{r, T}$ is the diffuse of radiation on the tilted surface. $I_{\mathrm{d}, \mathrm{T}}$ represent the reflecting sun's radiation on the panel surface.

$$
\begin{aligned}
& I_{b, T}=I_{b}(\cos \theta) \\
& I_{d, T}=I_{d}\left(\cos ^{2}\right) \frac{\beta}{2}\left[1+F \cdot \sin ^{3} \frac{\beta}{2}\right]\left[1+F\left(\cos \theta^{2}\right) \sin \theta^{3}\right] \\
& I_{r, T}=\rho \cdot\left(I_{b} \cdot \cos \theta z+I_{d}\right)\left(\sin ^{2}\right) \frac{\beta}{2}
\end{aligned}
$$

where: $I_{b}$ represent the normal ripening in the sun, $I_{d}$ : represent the horizontal solar diffuse, $\rho$ : albedo earth, $F$ : modulation factor, $\theta$ represent the angle between the sun and the normal tilted surface, $\theta z$ : represent the zenith angle of the Sun and $\beta$ represent the angle of panel inclination.

$$
\cos \cos \theta=\cos \cos \theta z \cos \beta+\sin \sin \theta z \sin \beta \cos \theta\left(\gamma_{s}-\gamma\right)
$$


The modulation factor $F$ of the cab is calculated as [14],

$$
F=1-\frac{I_{d}}{I_{t}}
$$

where: (Is) represent while sunlight dose over a horizontal area and is computed as [15],

$$
I_{t}=I_{b}(\cos \theta z)+\left(I_{d}\right)
$$

the angels for determining the ideal position of the panel are shown in Figure 2.

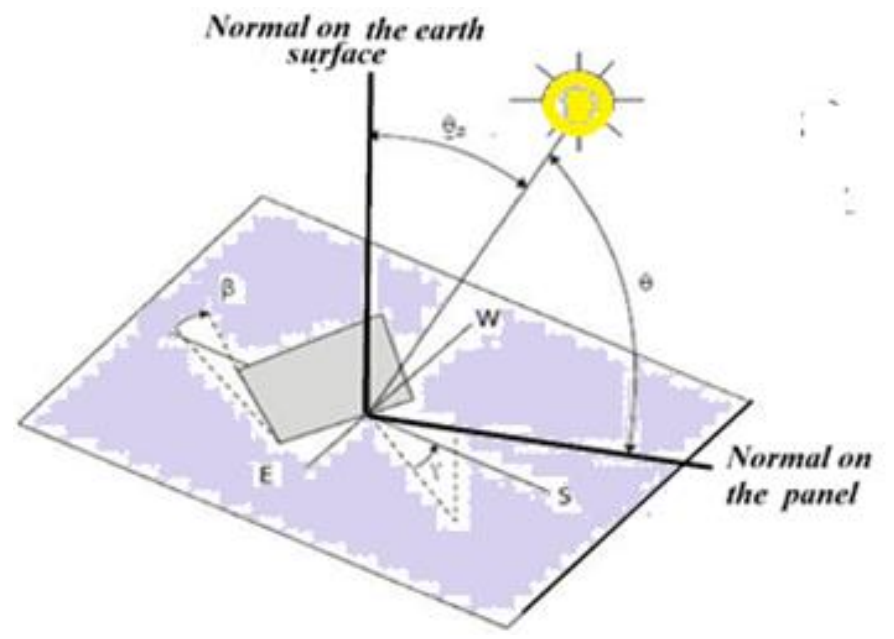

Figure 2. The angels for determining the optimal panel position [15]

\subsection{Calculation of thermal photovoltaic system temperature}

Temperature can be considered as an efficient factor that influences the photovoltaic panel operation. The small part of solar radiation fall on the panels is almost absorbed by the PV cells which whose task is to convert the absorbed energy into electrical energy, while the larger part is converted into thermal energy which led to rising the whole system temperature, which will transferred to the liquid that flow through the absorption tubes. The task of heat exchanger convection, conduction and radiation. Taking the previous parameters into account, the heat exchange module is obtained as (10) [16],

$$
C_{\text {Mod }} \frac{d t_{M o d}}{d T}=q_{L w}+q_{S w}+q_{W i t h}-P_{\text {Outside }}-Q_{t}
$$

where: $\mathrm{C}_{\text {mod }}$ is the thermal capacity of the modules, $d t_{\text {Mod }}$ is the module temperature, $q_{L w}$ is the of long wave radiation, $q_{S w}$ : è the short-chain radiation charge, $q_{W i t h}$ is the The thermal convection of the energy conduction, Pout is derived from the electrical energy panels and Qt being the thermal energy absorbed by the water. For accurate balancing, it is essential to know each specified component in the (10) in the following way:

\subsection{Heat capacity of the module $\left(C_{M o d}\right)$}

To determine the module's thermal capacity, the panel structure must be known. In this case, the module consists of three layers: glass roof, monocrystalline silicon photovoltaic cells and the absorption roof. The temperature of the modules is assumed to be the same in these layers. Every layer has own heat and temperature degree that will set to be equal the sum of all the layers and is dependent on the type and thickness of the material of each layer [17],

$$
C_{\text {Mod }}=\sum_{K=1}^{m} \text { Announcement } d_{K} \rho_{K} C_{K}
$$

where: (A) represents the panel surface, $(\mathrm{dk})$ is the single layer thickness, $(\rho \mathrm{k})$ is the layer thickness of each single layer, $(\mathrm{Ck})$ represents the temperature capability of the single layer. In such a case, the properties of every layer are given in Table 1 . The panel surface area is $(25) \mathrm{m}^{2}$. 
Table 1. Properties of layers of solar (PV) power module [18]

\begin{tabular}{lcccc}
\hline \multicolumn{1}{c}{ Low } & $\begin{array}{c}\rho_{\mathrm{k}} \\
\left(\mathrm{kg} / \mathrm{m}^{3}\right)\end{array}$ & $\begin{array}{c}\mathrm{dk} \\
(\mathrm{m})\end{array}$ & $\begin{array}{c}C_{K} \\
(\mathrm{~J} / \mathrm{kgK})\end{array}$ & $\begin{array}{c}\mathrm{C}_{\mathrm{Mod}} \\
(\mathrm{y} / \mathrm{k})\end{array}$ \\
\hline Monocrystalline & 2330 & $3 \times 10^{-3}$ & 676 & 11781 \\
Absorbent layer & 1200 & $5 \times 10^{-2}$ & 1250 & 18639 \\
Glass covers & 300 & $3 \times 10^{-2}$ & 500 & 112026 \\
\hline
\end{tabular}

\subsection{Heating transfer by the convection $\left(q_{\text {Conv }}\right)$}

It represents the transferring of the thermal energy between the ambient free space and panel surface that can be defined by using the (Newton's cooling legislation) between these two mediums as shown in the (12) [19],

$$
q_{\text {Conv }}=-h_{C} A\left(-T_{\text {Mod }}-T_{\text {With }}\right)
$$

where $h_{C}$ is both the natural and forced convection factor. The forced convection factor can be neglected where no winds are present. The factor of natural convection can be calculated by the following [19],

$$
\begin{aligned}
& h_{C, \text { free of charge }}=1.31 \cdot \sqrt[3]{T_{\text {Mod }}-T_{\text {with }}} \\
& b_{C, \text { forceed }}=(5.6)+v(3.8)
\end{aligned}
$$

where $v:$ is the wind speed. Through the mid-day, the convective heat transfer is the sum of both the natural and forced convection and it is given as (15) [19].

$$
q_{\text {Conv }}=A \cdot\left(h_{C, \text { free of charge }}+b_{C, \text { forced }}\right) \cdot\left(T_{\text {Mod }}-T_{\text {with }}\right)
$$

\subsection{PV panel output}

Electrical energy resulting at the output of the panel is the total maturation of the panel and its temperature. When the electrical power of the panels increases with the dose and decreases with the increase in temperature, the electrical energy in the panel output can be calculated by using the known table indicating the value of the electrical power obtained in the panel at a given dose and temperature of the panel. The table shall be presented as a matrix in the working solution of the program. The dimensions of the matrix are $1501 \times 101$, where the linear vector represents the total maturation on the inclined surface from $(1-1501) \mathrm{W} / \mathrm{m}^{2}$, while the column vector is the module temperature is $(30-70)^{\circ} \mathrm{C}$.

\subsection{The heat release obtained in the liquids}

The absorption factor represents the body ability to absorb the temperature of the sun, as transfer factor or the amount of solar dose passing through the panel frame. The system has an absorption pipe in which the cold-water flows and cause some dissipation of the thermal energy of the panels, causing a reduction in the temperature of the panel and thus the greater efficiency of the electrical energy panel obtained. At the same time, thermal energy is obtained which can be used to prepare hot water at home, greatly increasing the efficiency of the system as a whole. The thermal capacity of the panel $Q_{u}$ according to Hottel-Willier is [20],

$$
Q_{u}=A\left[L_{t t} .(\alpha \tau)-U_{L}\left(T_{M o d}-T_{w i t h}\right)\right.
$$

where : $\boldsymbol{U}_{\boldsymbol{L}}$ represent the thermal dissipation factor, $\alpha \tau$ is the product of absorption.

In (16) illustrates that an extremely non-linear heat losses factor exists. All parameters except the flow rate are dependent on the system's construction and the physical characteristics of the liquid [21]. The rate of thermal dissipation is very small as the mass flow increases. Therefore, according to (1), the electrical power of the pump is cubic as the flow rate increases, so that it can be derived that with a high liquid flow rate, the performance of the whole system will decrease [22].

Tables 2 and 3 show the most important parameters of the PV plant with their values. Other data changing in the time required for simulation (air temperature, surface irradiation and zenith angle) can be found in the work programming solution as a vector with a resolution of one minute [23]. The results presented are the irradiation of the panels on inclined surfaces, the panel temperature, the electrical output power of the photovoltaic panel and the net electrical output power of the system for the hot day 28 - 06 2018 at the University of Tikrit, Iraq. 
Table 2. Photovoltaic panel main parameters [24]

\begin{tabular}{lccc}
\hline \multicolumn{1}{c}{ Panel parameters } & Value & Panel parameters & Value \\
\hline Surface area (A) & $(25) \cdot \mathrm{m}^{2}$ & Absorption factor $(\alpha)$ & 0.80 \\
Total emission factor module coefficient $(\epsilon)$ & 0.90 & Transmission absorption factor & 0.52 \\
Thermal losses & $5\left(\mathrm{~W} / \mathrm{m}^{2} \mathrm{~K}\right)$ & Geometrical factor & 0.90 \\
\hline
\end{tabular}

Table 3. Characteristics of the pump [25], [26]

\begin{tabular}{lccc}
\hline \multicolumn{1}{c}{ Parameter } & Value & Parameter & Value \\
\hline losses coefficient $(\mathrm{K})$ & $(15)$ & Pipe jet $(\mathrm{r})$ & $10 \mathrm{~cm}$ \\
Fluid density $(\rho)$ & $\left(1000 \mathrm{~kg} / \mathrm{m}^{3}\right)$ & Capacity & $(50)$ Watt \\
Heating capacity $(\mathrm{c})$ & $4185(\mathrm{~J} / \mathrm{kg} . \mathrm{K})$ & panel inlet temperature & $\left(17^{\circ} \mathrm{C}\right)$ \\
\hline
\end{tabular}

\section{RESULTS AND DISCUSSION}

\subsection{Results of system optimization}

Figure 3 gives an illustration of the dependency of the overall panel dose on the overall radiation hitting the panel surface, whereas Figure 4 shows the dependent of the fluid flow on the panel temperature. Figure 5 illustrates the dependence of the panel output power on the flow of liquid, while Figure 6 illustrates the panel's efficiency in relation to the flow of liquid. The resulting simulations show that the panel temperature decreases to a maximum current of 15 Kelvin during the hottest part of the day (10 a.m. to 4 p.m.). The reduction of the panel temperature increases the electrical efficiency of the panel itself by $1.5 \%$ during the same day interval as shown in Figure 6. For the net electrical output power, it can be deduced from Figure 5 that the system is energy efficient at peak current only during the hottest part of the day. When the panel temperature does not exceed $400^{\circ} \mathrm{C}$, it is energy efficient and thus cools down the panel at the constant peak current as a small dose is applied to the panel in the morning and afternoon. The small dose of the panels reduces the electrical energy obtained from the panels, while the electrical energy built into the pump is kept constantly high, resulting in the inefficiency of the system as a whole. It is therefore the net electrical output power of solar panel the morning and afternoon is low. So, in this case, it is necessary to reverse the electrical power from the grid in order to achieve the intended pump performance. So, it is preferred to optimize the system so that the mass flow of the fluid in the system controls the total maturation of the panel.

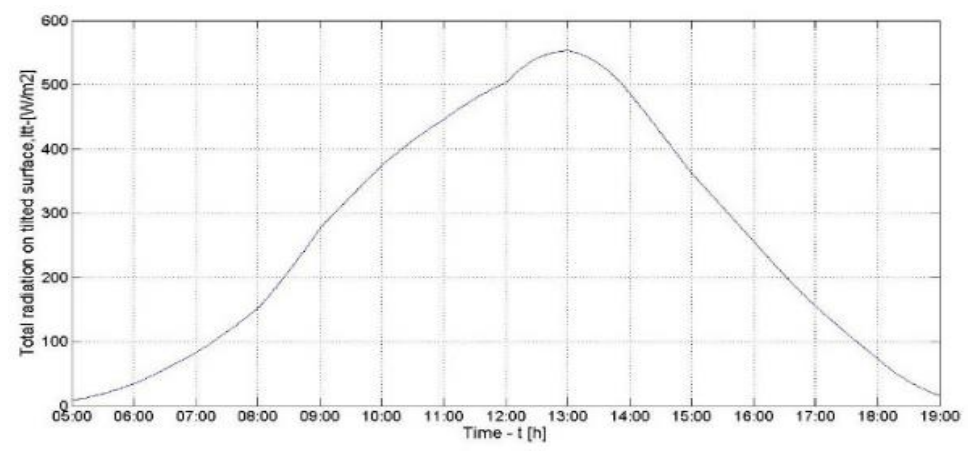

Figure 3. Total sun irradiance falls on the panel surface

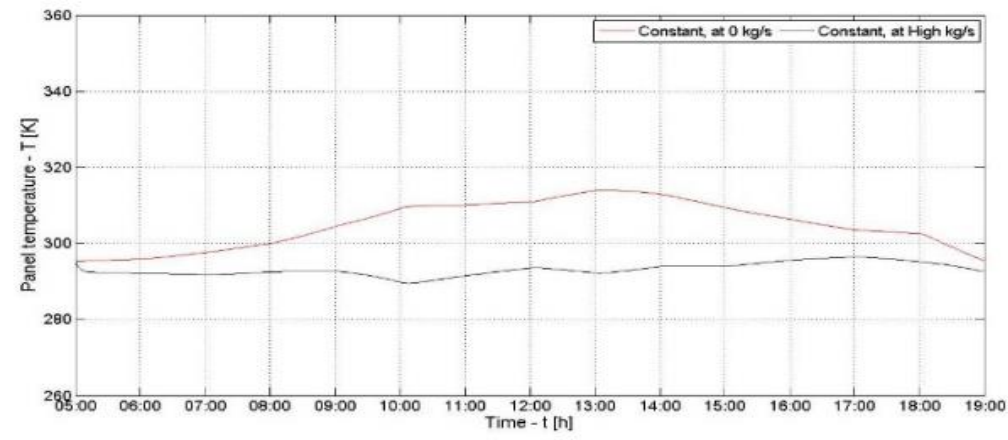

Figure 4. Temperature of PV/T panel before system optimization 


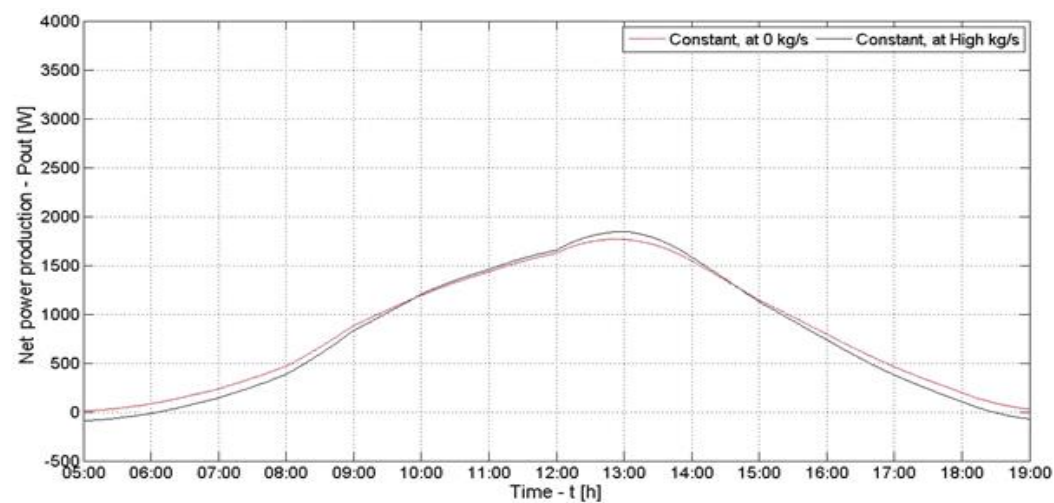

Figure 5. Output power of photovoltaic panel before system optimizing

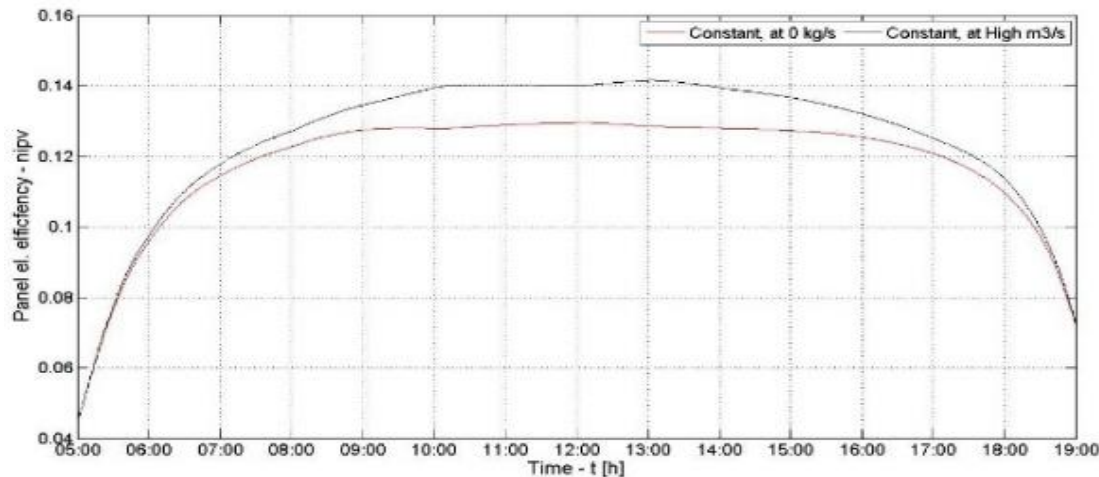

Figure 6. Photovoltaic panel efficiency before system optimizing

\subsection{Simulation results after system optimizing}

By using the finished algorithm which included in the job scheduling solutions, we obtained the optimal flow rate with a 15 minutes resolution. The optimal flow rate resulted for one-minute resolution in one day is shown in Figure 7. Figure 8 shows the simulation result of photovoltaic panel temperature variations for one day after system optimization. Figure 9 shows the simulation result of the optimum photovoltaic panel output power for one day after system optimization. Figure 10 illustrates the optimum simulation result of the (PV/T) efficiency of photovoltaic panel for one day after system optimization. The energy balance of the system is shown in Table 4. For the observed day when we use a single PV module, when we use a hybrid system (when the current is constantly high) and in case of optimizing flow.

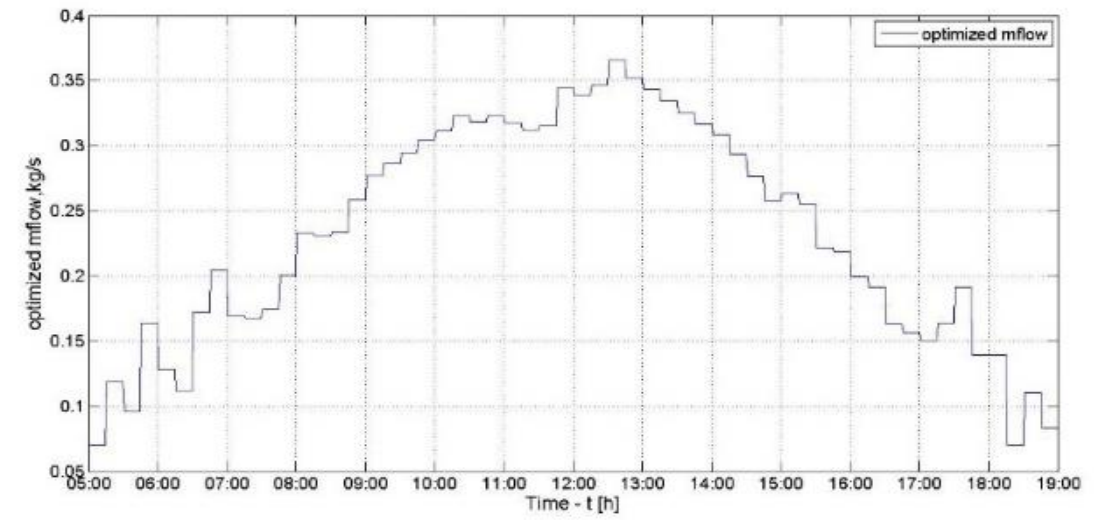

Figure 7. Optimizing fluid flow through the panel with a resolution of one minute 


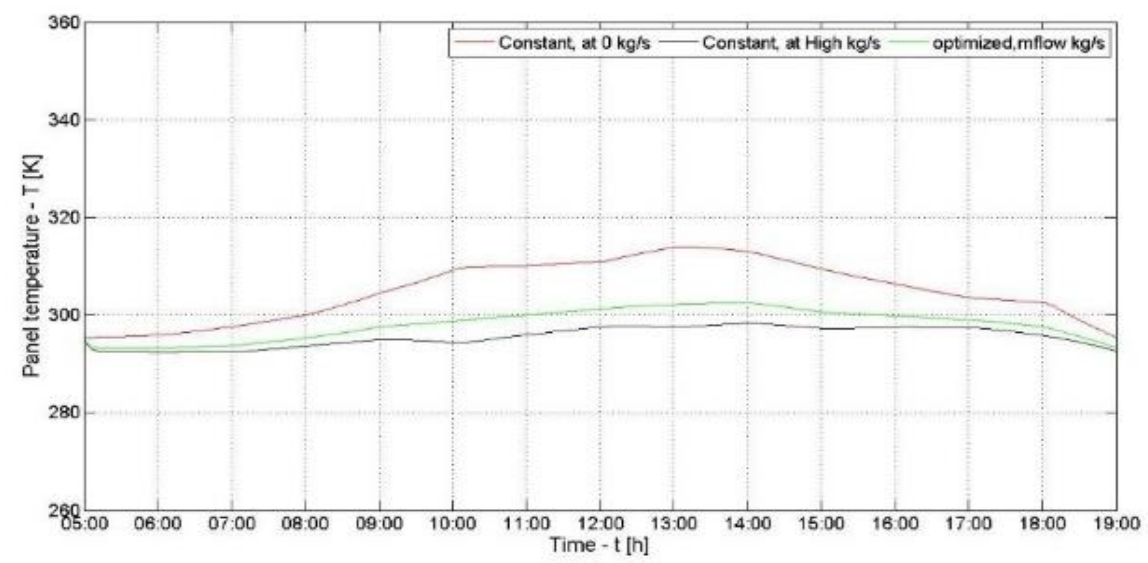

Figure 8. Photovoltaic panel temperature after system optimization

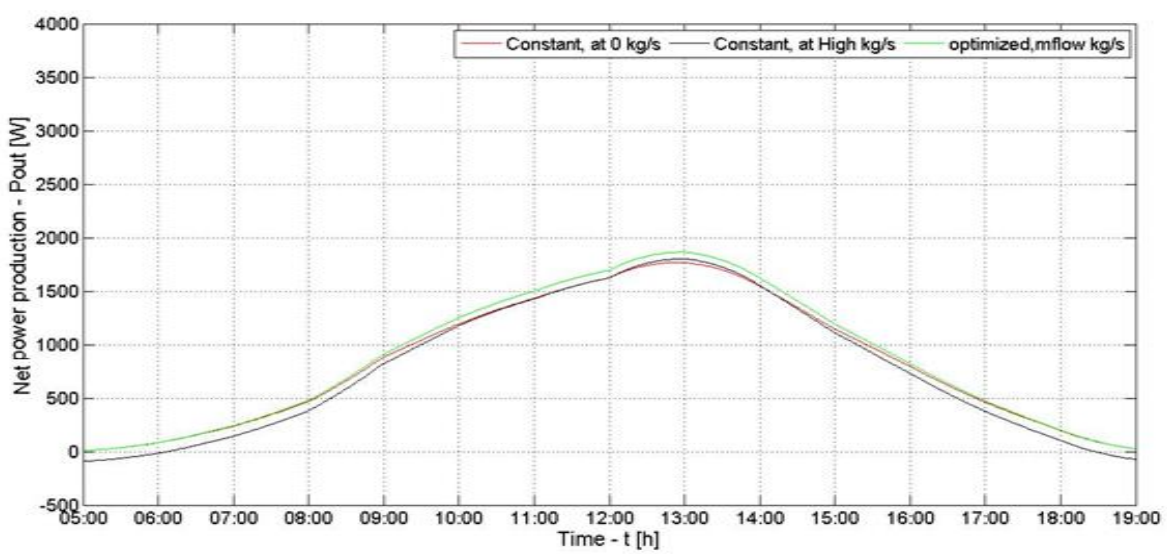

Figure 9. Output power of photovoltaic panel after system optimization

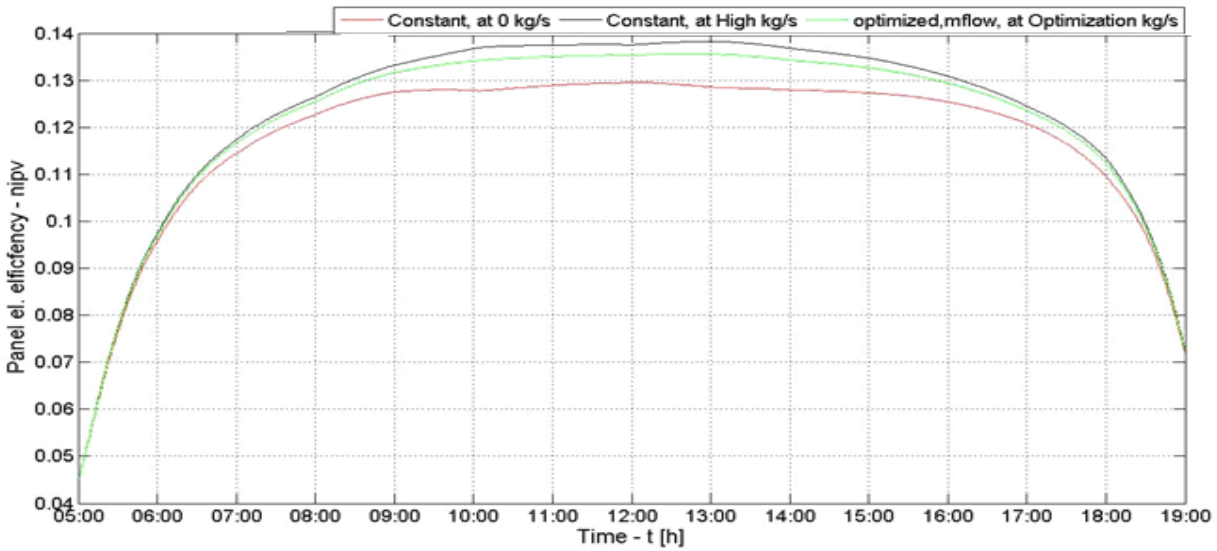

Figure 10. (PV/T) efficiency of photovoltaic panel after system optimization

Table 4. Energy balance of the system

\begin{tabular}{ccccc}
\hline PV/T Module type & $\begin{array}{c}\text { Average net of the electrical } \\
\text { power yield of the system [\%]. }\end{array}$ & $\begin{array}{c}\text { Average thermal efficiency } \\
\text { of the system [\%]. }\end{array}$ & $\begin{array}{c}\text { Overall } \\
\text { efficiency [\%]. }\end{array}$ & $\begin{array}{c}\text { Resulting thermal } \\
\text { energy [kWh]. }\end{array}$ \\
\hline Photovoltaic module & 12.03 & 0.00 & 12.20 & 0.00 \\
Constant Flow Module & 8.17 & 61.88 & 71.86 & 59.46 \\
Optimized flow module & 13.14 & 60.56 & 73.44 & 56.47 \\
\hline
\end{tabular}


From the results obtained, we can conclude that:

- The optimization algorithm has been conducted as illustrated in Figure 7. The optimizing flow controls the variation of the total dose at the panel, and then changes the panel temperature through the day. The result is a parabolic flow, which is to be expected as the lowest flow is needed in afternoon and morning when the panel temperature cooling is minimum, while the afternoon is highest because the panel temperature itself is higher. The result is a significant improvement in net panel power and overall system efficiency, as shown in Figures 8 and 9. Based on the optimized panel flow rate, the results of the panel temperature simulations, the net power of the photovoltaic-thermal system, the total electrical utility of the system is when the flow rate is zero, at optimizing flow rate.

- The optimizing algorithm aims to obtain a highest possible net output power. For the considered system, the function indicating the difference between the energy supplied by the panel and the power needed for the pump operation must have a maximum value. Mass flow management would be achieved by treating the electrical energy pumped to the pump with a resolution of 15 minutes. The simulation results obtained show that the electrical effictivnessof the whole system and the liquid energy system obtained has been significantly improved. There are no longer any efficiency losses for the period of the day when there is a small amount on the panel because it is a small flow through the system.

- At night and morning, the mass flow rate is around $(0.1) \mathrm{kg} / \mathrm{s}$, which requires only a few watts for the pump to operate, at a flow rate of about $(0.1) \mathrm{kg} / \mathrm{s}$. The needed electric power for pump is approximately (1.5) W. In the hottest daily hours, when the maximum panel temperature is needed to reduced, the mass flow rate increases for about $(0.41) \mathrm{kg} / \mathrm{s}$ during this period of the day, for which the pump power requirement is approximately $40.9 \mathrm{~W}$. So, during the day period, there is a good system management

\section{CONCLUSION}

The feasibility of a water-based photovoltaic system using a mathematical module have been investigated in which an experiment was carried out to analyses the water cooled photovoltaic and thermal system using the CFD method. In this study, a simple cooling system designed to reducing the solar panel temperature which consisting of a water piping and absorbing plate was simulated to establish the overall thermal efficiency. The combined analysis method of heating transfer was applied. The consequences of temperature fluctuations of inlet water as well as the absorbed irradiance have been taken into account.

Both the distribution of temperature on the solar panel and the temperature of the outgoing water have been estimated in the resulted temperature curves. The obtained results show a noticeable $\mathrm{n}$ rising in the electrical output power efficiency of about $(3.51 \%)$ with a reduction in system thermal efficiency in a range of about $(1.95 \%)$ compared with the system at a constant high flow rate. Compared to the PV module itself, we have an improvement in net electrical efficiency of $0.35 \%$. It should be noted that when analyzing the observed thermal system energy, the mean thermal efficiency is taken for the specific thermal capacity of the fluid flowing through the bottom of the panel, and not for the thermal capacity resulting from the tank heat exchanger, which results in a high thermal efficiency. Finally, the comparison between the results obtained by using the CFD simulation and the documentation experimental results are approximately identical.

\section{REFERENCES}

[1] Y. H. Yau and K. S. Lim, "Energy analysis of green office buildings in the Tropical Photovoltaic System," Energy and Building, vol. 126, pp. 177-193, 2016, doi: 10.1016/j.enbuild.2016.05.010.

[2] Y. Wang, S. Zhou and H. Hou, "Cost and $\mathrm{CO} 2$ reductions of solar photovoltaic power generation in China: Perspectives for 2020," Renewable and Sustainable Energy Reviews, vol. 39, pp. 370-80, 2020, doi: 10.1016/j.solener.2018.12.057.

[3] S. F. H. Correia, P. P. Lima, P. S. André, M. R. Sá Ferreira, and L. A. D. Carlos, "High-efficiency luminescent solar concentrators for flexible wave guiding photovoltaic," Sol. Energy Mater. Sol. Cells, vol. 138, pp. 51-57, 2015, doi: 10.1016/j.solmat.2015.02.032.

[4] R. M. Da Silva and J. L. M. Fernandes, "Simulation of hybrid photovoltaic/thermal (PV/T) solar systems with Simulink/ MATLAB,” Sol. Energy, vol. 84, pp. 1985-96, 2010, doi: 10.1016/j.solener.2010.10.004.

[5] K. K. Tse, T. T. Chow, and Y. Su, "Performance assessment and economic analysis of a water based photovoltaic/thermal (PV/T) system in an office building," Energy and Buildings, vol. 122, pp. 42-52, 2016, doi: 10.1016/j.apenergy.2015.11.053.

[6] T. Selmi, M. Abdul-Niby, L. Devis, and A. Davis, "P\&O MPPT implementation using MATLAB/Simulink," 2014 Ninth International Conference on Ecological Vehicles and Renewable Energies (EVER), 2014, pp. 1-4, doi: 10.1109/EVER.2014.6844065.

[7] J. P. da Cunha and P. Eames, "Thermal energy storage for low and medium temperature applications with phase changing materials-a review," Apply Energies, vol. 177, pp. 227-38, 2016, doi: 10.1016/ j.enconman.2016.11.002. 
[8] S. Bhattarai, J-H. Oh, S-H. Euh, G. K. Kafle, and D. H. Kim, "Simulation and model validation of sheet and tube type photovoltaic thermal solar system and conventional solar collecting system in transient states," Solar Energy Materials and Solar Cells, vol. 103, pp. 148-193, 2012, doi: 10.1016/j.solmat.2012.04.017.

[9] D. Su, Y. Jia, G. Alva, L. Liu, and G. Fang, "Comparative analysis of the dynamic performance of solar thermal collectors integrated with phase shifting materials," Energy Conversion and Management, vol. 131, pp. 79-89, 2017, doi: 10.1016/j.enconman. 2016.11.002.

[10] P. Haurant, P. Oberti, and M. Muselli, "Multicriteria selection aiding of photovoltaic plants on farming fields in Corsica Island: a real case study in the ELECTRE outranking framework," Energy Policy, vol. 39, no. 2, pp. 676688, 2011, doi: 10.1016/ j.egypro.2019.01.264.

[11] P. Haurant, C. Ménézo, L. Gaillard, and P. Dupeyrat, "A numerical model of a solar domestic hot water system integrating hybrid photovoltaic/thermal collectors," Energy Procedia, vol. 78, pp. 1991-1997, 2015, doi: 10.1016/j.egypro.2015.11.391.

[12] Z. Qiu, X. Ma, X. Zhao, P. Li, and S. Ali, "Experimental investigation of the energy performance of a novel Microencapsulated Phase Change Material (MPCM) slurry based PV/T system," Applied Energy, vol. 165, pp. 260-271, 2016, doi: 10.1016/j.enpol.2010.10.040.

[13] A. Sahay, V. K. Sethi, A. C. Tiwari, and M. Pandey, "A review of solar photovoltaic panel cooling systems with special reference to Ground coupled central panel cooling system (GC-CPCS)," Renewable and Sustainable Energy Reviews, vol. 42, pp. 306-312, 2014, doi: 10.1016/j.rser.2014.10.009.

[14] A. Tiwari and M. S. Sodha, "Performance evaluation of solar PV/T system: An experimental validation," Solar Energy, vol. 80, pp. 751-759, 2006, doi: 10.1016/j.solener.2005.07.006.

[15] D. Su, Y. Jia, G. Alva, L. Liu, and G. Fang, "Comparative analyses on dynamic performances of photovoltaicthermal solar collectors integrated with phase change materials," Energy Conversion and Management, vol. 131, pp. 79-89, 2017, doi: 10.1016/j.enconman.2016.11.002.

[16] M. M. Sarafraz et al., "Experimental investigation on thermal performance of a PV/T-PCM (photovoltaic/thermal) system cooling with a PCM and nanofluid," Energies, vol. 12, no. 3, 2019, doi: 10.3390 / en 12132572.

[17] P. Rajput, G. N. Tiwari, and O. S. Sastry, "Thermal modelling and experimental validation of hot spot in crystalline silicon photovoltaic modules for real outdoor condition," Solar Energy, vol. 139, pp. 569-580, 2016, doi: 10.1016/j.solener.2016.10.016.

[18] M. Rezvanpour, D. Borooghani, F. Torabi, and M. Pazoki, "Using $\mathrm{CaCl} 2 \cdot 6 \mathrm{H} 2 \mathrm{O}$ as a phase change material for thermo-regulation and enhancing photovoltaic panels, conversion efficiency: Experimental study and TRNSYS validation," Renewable Energy, vol. 146, pp. 1907-1921, 2020, doi: 10.1016/ j.renene.2019.07.075.

[19] B. Vishwanathan et al., "A comparison of the performance of flat and curved luminous solar concentrators," Solar Energy, vol. 112, pp. 120-127, 2015, doi: 10.1016/J.RENENE.2018.02.002.

[20] R. Pegado, Z. Ñaupari, Y. Molina, and C. Castillo, "Radial distribution network reconfiguration for power losses reduction based on improved selective BPSO," Electr. Power Syst. Res., vol. 169, pp. 206-213, 2019, doi: 10.1016/j.solener.2020.01.015.

[21] T. T. Nguyen, T. T. Nguyen, A. V. Truong, Q. T. Nguyen, and T. A. Phung, "Multi-objective electric distribution network reconfiguration solution using runner-root algorithm," Appl. Soft Comput., vol. 52, pp. 93-108, 2017, doi: 10.1016/j.apenergy.2019.01.103.

[22] D. Su, Y. Jia, G. Alva, L. Liu, and G. Fang, "Comparative analyses on dynamic performances of photovoltaicthermal solar collectors integrated with phase change materials," Energy Conversion and Management, vol. 131, pp. 79-89, 2017, doi: 10.1016/j.enconman.2016.11.002.

[23] F. Selimefendigil, F. Bayrak, and H. F. Oztop, "Experimental analysis and dynamic modeling of a photovoltaic module with porous fins," Renewable Energy, vol. 125, pp. 193-205, 2018, doi: 10.1016/J.RENENE.2018.02.002.

[24] K. J. Ali, A. H. Mohammad, and G. T. Hasan, "An empirical correlation of ambient temperature impact on PV module considering natural convection" Indonesian Journal of Electrical Engineering and Computer Science, vol. 19, no. 2, pp. 627-634, Aug. 2020, doi: 10.11591/ijeecs.v19.i2.pp627-634.

[25] M. K. Panjwani et al., "Hybrid concentrated photovoltaic thermal technology for domestic water heating," Indonesian Journal of Electrical Engineering and Computer Science, vol. 16, no. 3, pp. 1136-1143, Dec. 2019, doi: 10.11591/ijeecs.v16.i3.pp1136-1143.

[26] S. R. Salkuti, "Optimal operation management of Grid-Connected microgrids under uncertainty," Indonesian Journal of Electrical Engineering and Computer Science, vol. 16, no. 3, pp. 2502-4752, Dec. 2019, doi: 10.11591/ijeecs.v16.i3.pp1163-1170. 


\section{BIOGRAPHIES OF AUTHORS}
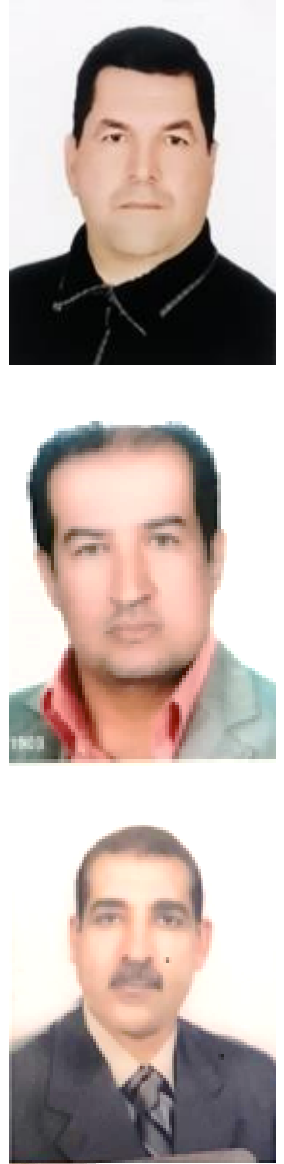

Nabeel Muhamedakram Samad, born in kirkuk, Iraq, holds a Bachelor's degree in Electrical Engineering from the Technical Northern University. Technical college / Kirkuk / Iraq Republic of Bosnia 2006, completed a master's degree in electrical engineering in 2013, Faculty of Electrical Engineering, currently works as a lecture. Assist. in the Department of Electrical Engineering, published several scientific researches in electrical engineering and computer science.

Khaleel Ali Khudhur, born in Kirkuk city, Iraq, holds a Bachelor's degree in Electrical Engineering from the Technical Northern University. Technical college / Kirkuk / Iraq Republic of Bosnia 2007, completed a master's degree in electrical engineering in 2011, Faculty of Electrical Engineering, currently works as a lecture. Assist. in the Department of Electrical Engineering, published several scientific researches in his field of competence.

Ghanim Thiab Hasan, Born in Salah al-Din, Iraq, holds a Bachelor's degree in Electrical Engineering from the University of Sarajevo, Republic of Bosnia 1984, completed a master's degree in electrical engineering at the University of Belgrade in 1986, Faculty of Electrical Engineering, currently works as a Prof. Assist. in the Department of Electrical Engineering, published several scientific researches in his field of competence. Tikrit university, Al-Sharqat engineering college, Republic of Iraq. 